\section{Detection of Lumbar Facet Joint Gouty Arthritis Using Dual-energy Computed Tomography}

\section{To the Editor:}

Gout (monosodium urate crystal deposition disease) has been estimated to affect 3 to 6 million Americans, and both the incidence and prevalence appear to be increasing ${ }^{1}$. Gout is characterized by serum urate supersaturation, extracellular tissue deposition of urate crystals in and around joints, and acute inflammatory episodes. In unusual cases, patients may present with tophaceous deposits in the absence of, or prior to, development of gouty arthritis ${ }^{2}$. Although acute gout typically affects peripheral joints, involvement of the axial skeleton has been recognized ${ }^{3}$. Dual-energy computed tomography (DECT) is a technique that is able to identify tophaceous deposits, which have a distinctive appearance. We describe a case of gouty lumbar facet arthritis utilizing DECT.

An 82-year-old Caucasian man with a history of obesity, type 2 diabetes, ischemic cardiomyopathy, atrial fibrillation, and chronic kidney disease presented with a complaint of acute on chronic low back pain. The back pain had increased significantly over the previous year, with new radiation of pain, numbness, and tingling down his right leg. The back pain was chronic with superimposed flares. He also experienced subacute flares of pain and swelling of knees and hands over recent months. Over the past 6 months he had noted gradual evolution of nodular whitish deposits about several finger joints.

Examination revealed nodules, characteristic of tophaceous deposits, about several proximal interphalangeal (PIP) joints, olecranon processes bilaterally, and toes, with associated mild soft tissue swelling. There was

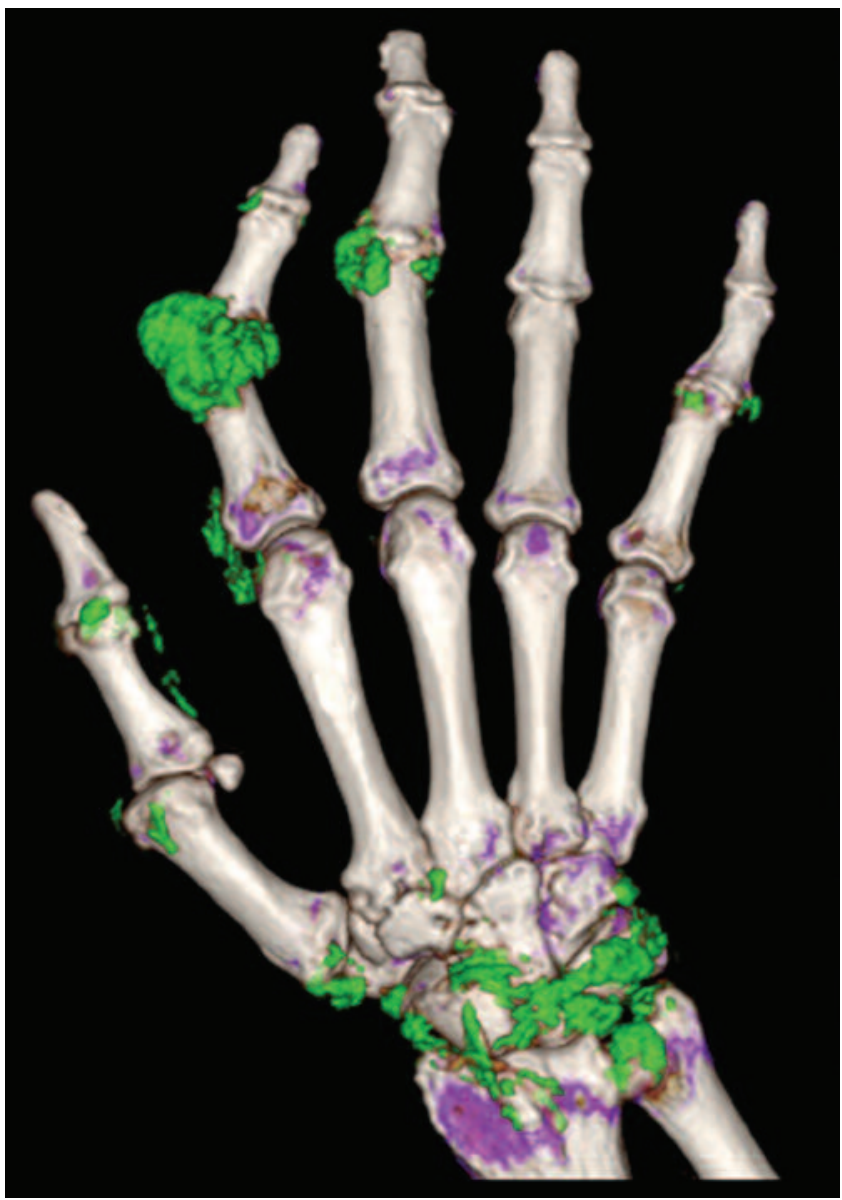

Figure 1. Dual-energy computed tomography image reveals extensive urate crystal deposition throughout the hand. decreased range of motion of wrists and cervical and lumbar spine. Creatinine concentration was $1.9 \mathrm{~g} / \mathrm{dl}$ and uric acid $11.8 \mathrm{mg} / \mathrm{dl}$. Plain radiographs of his right hand revealed marginal erosions and soft tissue swelling of multiple PIP joints. A DECT scan of the right hand (Figure 1) confirmed the presence of tophaceous deposits. DECT of the lumbar spine (Figure 2), to evaluate for possible gouty contribution to his increased low back pain, revealed uric acid deposition in the right L2-L3, L4-L5, and L5-S1 facet joints. A lumbar magnetic resonance imaging (MRI) scan performed 2 days previously had revealed multilevel disc disease and foraminal narrowing, but did not identify urate deposits. Colchicine was given and subsequently febuxostat $40 \mathrm{mg}$ daily was prescribed. Two months after start of this medication, the uric acid had fallen to $8.3 \mathrm{mg} / \mathrm{dl}$. A repeat DECT scan of the right hand revealed $8.3 \%$ reduction of urate volume. The patient was referred to the pain clinic for facet joint injections. Aspiration of the right L4-L5 facet revealed multiple uric acid crystals by polarized microscopy.

Several modalities are available to aid in diagnosis of suspected gouty arthritis and tophaceous deposits including synovial fluid analysis, plain radiography, CT, MRI, and ultrasonography. While radiographic changes may be associated with loss of function and typically highlight joint damage, they are less sensitive to early changes in chronic gout ${ }^{4}$. CT has been shown to be more specific than MRI or ultrasonography in the identification of tophi ${ }^{5}$. MRI has been shown to be of value when evaluating synovial involvement, but at higher cost to the patient ${ }^{6}$. Ultrasonography may suggest early deposition of uric acid crystals and may reveal synovial thickening and inflammation but its use is largely limited to peripheral joints ${ }^{7}$. Although ultrasonography and CT may assist in direct aspiration of a joint for crystal evaluation, neither can specifically identify uric acid crystal deposition. DECT has been used to detect cardiovascular calcifications and compositional analysis of kidney stones through identification of calcium and uric acid by color coding ${ }^{8,9}$. DECT has also been shown to be

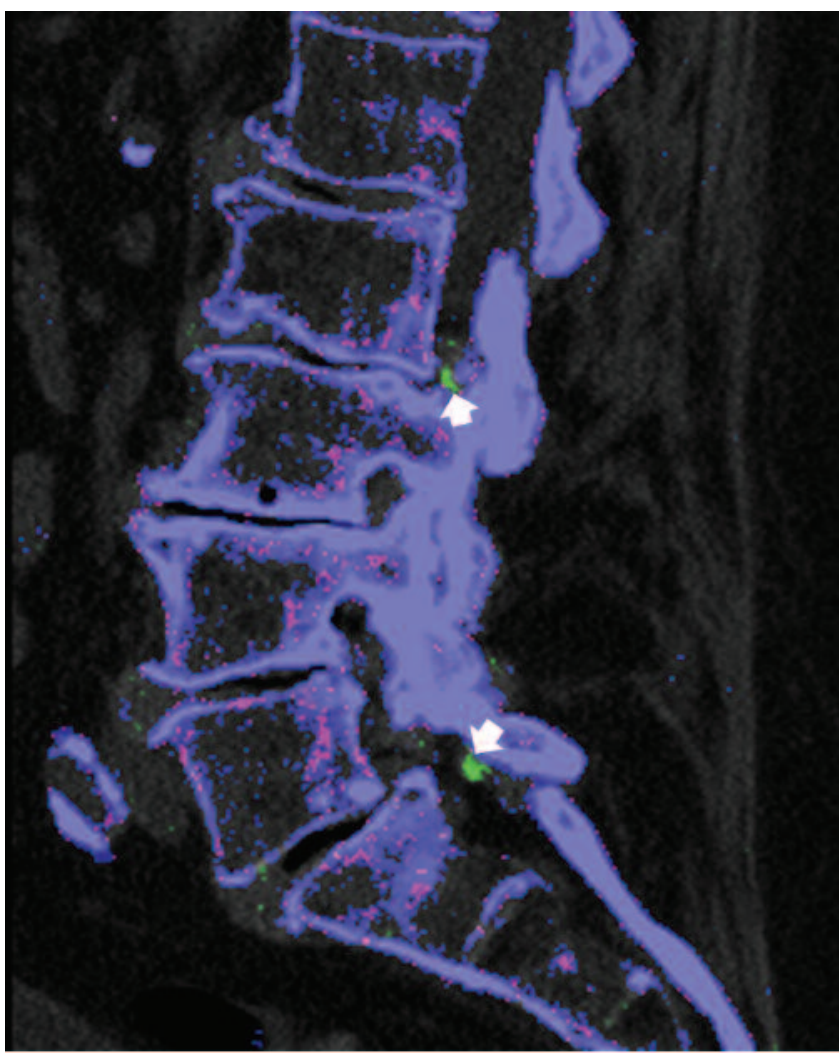

Figure 2A. Dual-energy computed tomography scan of the spine shows focal uric acid deposits, depicted in green (white arrows), associated with L2-L3 and L5-S1 facet joints (Figure 2B overleaf). 


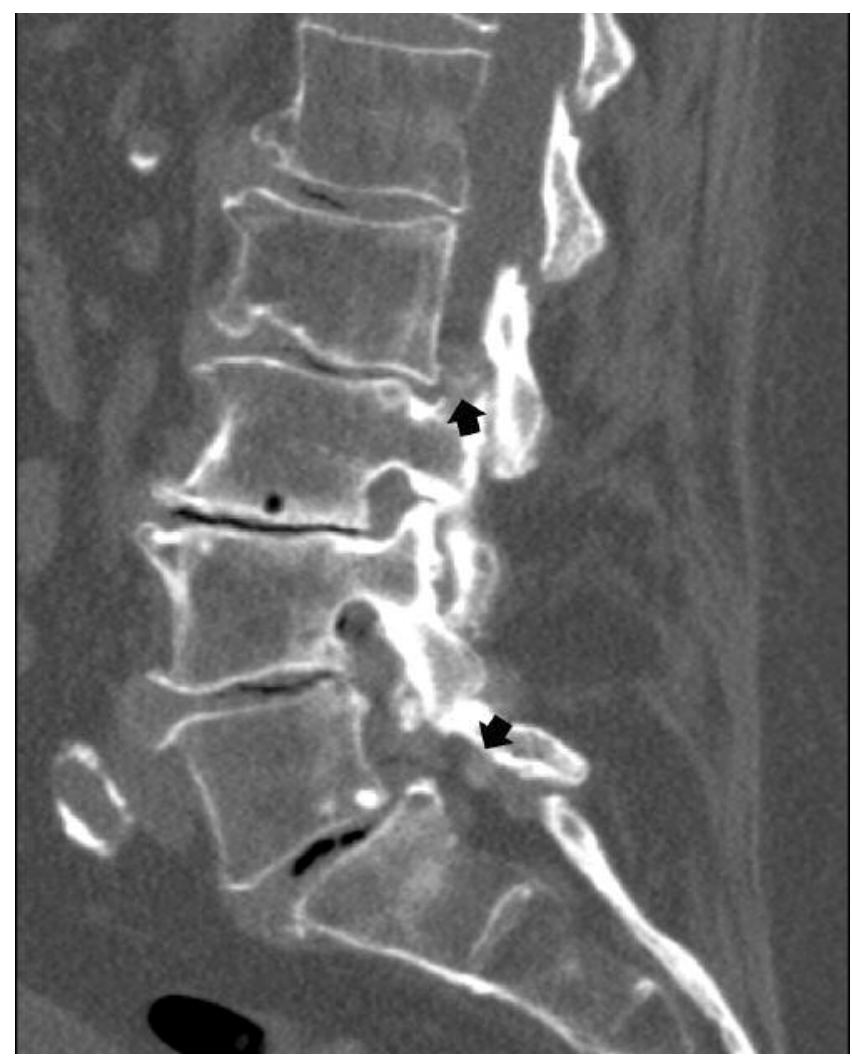

Figure 2B. Corresponding conventional CT image shows the tophi as nonspecific areas of mildly increased attenuation (black arrows).

useful in specifically identifying uric acid deposits in patients with subclinical tophi and gout ${ }^{10}$.

To our knowledge, this is the first reported case utilizing DECT to diagnose uric acid crystal deposition in the spine, confirmed by analysis of aspirated material. Although the diagnosis of acute gout of a peripheral joint can be confirmed by joint aspiration and crystal analysis, the diagnosis in patients with axial symptoms, such as those arising from the facet joints of the spine, is more difficult. Neither plain radiographs, nor ultrasonography, nor MRI has been shown to consistently and specifically reveal gouty involvement of the spine. Older patients typically have evidence of spondylosis that might account for back symptoms. In patients who have known recurrent back pain with a history of hyperuricemia and typical gouty arthritis, DECT may be useful in detection of axial uric acid deposits. DECT may facilitate the diagnosis of gout of the spine and allow specific treatment with the expectation of an improved clinical outcome.

PRAGNESH PARIKH, MD; RONALD BUTENDIECK, MD; MARK KRANSDORF, MD; KENNETH CALAMIA, MD, Departments of Internal Medicine, Radiology and Rheumatology, Mayo Clinic, Jacksonville, Florida, USA. Address correspondence to Dr. Calamia;

E-mail: calamia.kenneth@mayo.edu

\section{REFERENCES}

1. Lawrence RC, Felson DT, Helmick CG, Arnold LM, Choi H, Deyo RA, et al. National Arthritis Data Workgroup. Estimates of the prevalence of arthritis and other rheumatic conditions in the United States. Part II. Arthritis Rheum 2008;58:26-35.

2. Wernick R, Winkler C, Campbell S. Tophi as the initial manifestation of gout. Report of six cases and review of the literature. Arch Intern Med 1992;152:873-6.

3. Konatalapalli RM, Demarco PJ, Jelinek JS, Murphey M, Gibson $\mathrm{M}$, Jennings B, et al. Gout in the axial skeleton. J Rheumatol 2009;36:609-13.

4. Nakayama DA, Barthelemy C, Carrera G, Lightfoot RW, Wortmann RL. Tophaceous gout: a clinical and radiographic assessment. Arthritis Rheum 1984;27:468-71.

5. Gerster JC, Landry M, Dufresne L, Mewly JY. Imaging of tophaceous gout: computed tomography provides specific images compared with magnetic resonance imaging and ultrasonography. Ann Rheum Dis 2002;61:52-4.

6. Popp JD, Bidgood WD Jr, Edwards LN. Magnetic resonance imaging of tophaceous gout in the hands and wrists. Semin Arthritis Rheum 1996;25:282-9.

7. Puig JG, de Miguel E, Castillo MC, Rocha AL, Martinez MA, Torres RJ. Asymptomatic hyperuricemia: impact of ultrasonography. Nucleosides Nucleotides Nucleic Acids 2008;27:592-5.

8. Reimann AJ, Rinck D, Birinci-Aydogan A, Scheuering M, Burgstahler C, Schroeder S, et al. Dual-source computed tomography: advances of improved temporal resolution in coronary plaque imaging. Invest Radiol 2007;42:196-203.

9. Graser A, Johnson TR, Bader M, Staehler M, Haseke N, Nikolaou $\mathrm{K}$, et al. Dual energy CT characterization of urinary calculi: initial in vitro and clinical experience. Invest Radiol 2008;43:112-9.

10. Choi HK, Al-Arfaj AM, Eftekhari A, Munk PL, Shojania K, Reid $\mathrm{G}$, et al. Dual energy computed tomography in tophaceous gout. Ann Rheum Dis 2009;68:1609-12.

J Rheumatol 2010;37:10; doi:10.3899/jrheum.100492 